\title{
A EFICIÊNCIA DE MERCADO FUTURO DO CAFÉ NO BRASIL: UMA ABORDAGEM POR MEIO DA REGRESSÃO QUANTÍLICA
}

Augusto Weslley de Araújo ${ }^{1}$ Tarcísio da Costa Lobato ${ }^{2}$ Viviane Silva Lirio $^{3}$

Resumo: O presente artigo pretende verificar a eficiência do mercado futuro brasileiro para a commodity café arábica, de acordo com os contratos negociados na B3 no período de 2007 a 2017. Para isto, aplicou-se o método dos mínimos quadrados ordinários e regressão quantílica. Os resultados indicaram que as séries são estacionárias de 1a ordem e o teste de Engle e Granger indicou que os modelos são cointegrados. Os testes dos resíduos impossibilitaram a interpretação do MQO, indicando que seu uso não é adequado. Entretanto, o mesmo não ocorre com a regressão quantílica, que apresentou no longo prazo um aumento da taxa ótima e da eficiência de mercado, com prêmio ao risco onde as oscilações de preços foram maiores e no curto prazo ocorre o oposto.

Palavras-chave: Eficiência de mercado. Café. Regressão quantílica.

\section{THE EFFICIENCY OF THE FUTURE MARKET OF COFFEE IN BRAZIL: AN APPROACH THROUGH QUANTILE REGRESSION}

Abstract: The present paper intends to verify the brazilian future market's efficiency for the arabica coffee, according to the contracts negotiated in B3 between 2007 and 2017. For this, the method of ordinary least squares and quantile regression was applied. The results indicated that the series are stationary of first order and the test of Engle and Granger indicated that the models are cointegrated. The residue tests made it impossible to interpret the OLS, indicating that its use is not adequate. However, the same does not occur with the quantile regression, which presented in the long term an increase of the optimal rate and the market efficiency, with risk premium where the price oscillations were higher and in the short term the opposite occurs.

Keywords: Market efficiency. Coffee. Quantum regression.

\section{LA EFICIENCIA DEL FUTURO MERCADO DEL CAFÉ EN BRASIL: UN ENFOQUE A TRAVÉS DE LA REGRESIÓN CUANTIL}

Resumen: El presente documento pretende verificar la eficiencia del mercado futuro de Brasil para el producto de café Arábica, según los contratos negociados en B3 desde 2007 hasta 2017. Para esto, se aplicó el método de mínimos cuadrados ordinarios, y la regresión por cuantiles. Los resultados indicaron que las series son estacionarias de primer orden y la prueba de Engle y Granger indicaron que los modelos están cointegrados. Las pruebas de residuos hicieron imposible interpretar el MCO, lo que indica que su uso no es adecuado. Sin embargo, no ocurre lo mismo con la regresión por cuantiles, que presentó a largo plazo un aumento de la tasa

1 Universidade Federal de Viçosa, Departamento de Economia Rural. Viçosa, Brasil, augustooficial018@gmail.com, https://orcid.org/0000-0002-0429-1824

2 Universidade Federal do Oeste do Pará, Instituto de Ciências da Sociedade, Santarém, Brasil, tarcisolobatol@yahoo.com.br, https://orcid.org/0000-0002-2002-5622

3 Universidade Federal de Viçosa, Departamento de Economia Rural, Viçosa, Brasil,viviani.lirio@gmail.com, https://orcid.org/0000-0001-6806-819X 
óptima y la eficiencia del mercado, con una prima de riesgo donde las oscilaciones de los precios fueron mayores y, a corto plazo, ocurre lo contrario.

Palabras claves: Eficiencia de mercado. El café. Regresión cuántica.

\section{INTRODUÇÃO}

A atividade agropecuária possui elevada importância para a economia brasileira, uma vez que contribui diretamente na composição do Produto Interno Bruto (PIB) do Agronegócio que impacta o PIB nacional, tanto em termos de produção (além da geração de emprego e renda) quanto por meio das exportações de commodities agrícolas, contribuindo para um saldo positivo na balança comercial brasileira. Um dos produtos que historicamente contribuem para esse cenário positivo é o café, por sua expressividade de mercado e por seu grau de estabilidade nas negociações e preços e por sua alta demanda no mercado internacional.

A partir da expressiva importância do mercado cafeeiro no Brasil, salienta-se que devem existir mecanismos de controle que facilitem o processo de comercialização das commodities agrícolas, tais como os mercados futuros, de modo, que seja possível estabelecer um nível estável de preços, tendo em vista as oscilações do mercado. Assim, utiliza-se como ferramenta de gerenciamento de risco o "contrato futuro" que pode ser designado como "um acordo de compra ou venda de um ativo a um determinado preço, com dada quantidade de produto, para ser entregue em determinado local, com liquidação em data futura pré-estabelecida" (HARZER et. al., 2012).

Quando se busca avaliar um mercado, deve-se entender um pouco da sua dinâmica e do seu funcionamento, a partir disso, observa-se que o mercado de café arábica em 2016 obteve uma produção histórica com um total de 51,37 milhões de sacas, sendo $72,17 \%$ exportados, um aumento de produção de $18,8 \%$. O resultado positivo foi reflexo do aumento do consumo mundial, das condições climáticas favoráveis aliadas ao ciclo de bienalidade 4 positiva. Em 2017 a produção alcançou 44,97 milhões de sacas, o que revela uma retração produtiva comparado a safra de 2016, a produção do café arábica foi de 38,3 milhões de sacas reduzindo $6.4 \%$. Essa oscilação advém além da esperada retração bienal da safra do café arábica, porém também devido ao surto da broca do café. Em 2018 a produção alcançou 61,7 milhões de sacas, uma elevação de $37,1 \%$ comparado a safra do ano anterior,

\footnotetext{
${ }^{4} \mathrm{~A}$ bienalidade de produção do café é um fenômeno marcante da cafeicultura brasileira. Resulta em diferenciais expressivos na produção de frutos e nas safras colhidas. A bienalidade ou diferencial produtivo, a cada ano, pode ocorrer entre talhões de lavouras, entre plantas da mesma lavoura e, ainda, dentro da própria planta, uma parte produzindo bem num ano e a outra no ano seguinte (CONAB, 2018).
} 
devido principalmente a bienalidade positiva na maioria das regiões produtoras (CONAB, 2018).

Nesse sentido, tendo em vista o potencial e a expressividade do mercado cafeeiro no Brasil, esse trabalho busca (i) investigar a relação entre os preços futuro e o preço à vista desta commodity ${ }^{5}$, e (ii) verificar se os preços futuros correntes são estimadores não viesados dos preços à vista esperados de café arábica, utilizando a técnica da regressão quantílica, entre janeiro de 2007 e dezembro de 2017 dos contratos negociados na B3 (BRASIL BOLSA BALCÃO), comparando com os preços à vista do CEPEA-ESALQ (CENTRO DE ESTUDOS AVANÇADOS EM ECONOMIA APLICADA-ESCOLA SUPERIOR DE AGRICULTURA "LUIZ QUEIROZ") para a região noroeste do Paraná.

Para alcançar essa proposta este estudo está subdividido em seis seções, a primeira seção corresponde a esta introdução, a segunda discutirá os instrumentos de derivativos, os conceitos e componentes do mercado futuro e o que é considerado eficiência de mercado. A terceira seção dedica-se a revisão de literatura sobre os principais trabalhos no Brasil que investigam a eficiência de mercado de produtos agrícolas. A quarta seção será dedicada aos procedimentos metodológicos empregados no trabalho, como banco de dados, modelos e testes utilizados. $\mathrm{Na}$ quinta seção será abordado os principais resultados advindos da pesquisa e na seção seis as principais considerações do trabalho serão relatadas.

\section{REFERENCIAL TEÓRICO}

Tendo em vista que a agricultura é um setor sujeito ao risco, e que não possui instrumentos suficientes para garantir uma securitização de $100 \%$ da produção, a teoria do portfólio e do hedge propõem, fundamentalmente, a determinação de uma razão de hedge que satisfaça as preferências do investidor quanto ao risco e ao retorno que deseja assumir. Para tanto, Gomes (1987) aborda o hedging como uma decisão de investimento onde os diversos ativos são de fato diferentes proporções de dois ativos básicos:

a) a mercadoria (não-hedge);

b) o hedge completo (teoria clássica).

${ }^{5}$ Commodity corresponde a um produto de qualidade e característica uniforme, não são diferenciados de acordo com quem os produziu ou de sua origem, sendo seu preço determinado pela oferta e demanda. 
Nessa perspectiva, existirá uma razão ótima de hedge para cada investidor, uma vez que estes possuem diferentes estruturas de preferência quanto ao risco. A teoria do portfólio aborda essa questão de forma mais sistemática e abrangente que as demais, tendo em vista que busca descentralizar os investimentos do investidor em uma carteira, que distribui os riscos que estariam concentrados em um ativo subjacente. A justificativa econômica clássica para a existência dos mercados futuros é que estes facilitam o hedging, permitindo aos hedges (agentes econômicos envolvidos) a partir da estocagem de dada mercadoria, transferir os riscos associados às flutuações de preço a outros agentes denominados especuladores (HAZER et al., 2012).

GOMES (1987) destaca que parcela significativa do problema de hedging corresponde à determinação da proporção entre as quantidades da mercadoria que o hedger manterá nos mercados físicos e futuros: a razão de hedge. Nesse sentido, evidencia-se que as teorias de hedging, podem ser dispostas em dois grandes grupos, a partir da ênfase emprega pelos modelos:

I- Sobre o risco; - teoria clássica e teoria minimizadora;

II- Sobre o risco-retorno; - teoria da especulação na base e teoria do portfólio.

Nesse sentido, como mecanismos de gerenciamentos de riscos, existem alguns instrumentos de derivativos que possibilitam uma diminuição do risco das oscilações de preço dos ativos, como os de mercado futuro, mercado de opções, mercado a termo e swaps. Bitencourt (2007) enfatiza que os instrumentos de derivativos constituem um importante meio para a atividade de gerenciamento do risco de oscilações de preços no mercado, algumas de suas vantagens são: a reversibilidade de contratos, a operação continuada no mercado, a alocação intertemporal dos recursos para verificar se os preços do futuro são um estimador do preço físico, e a possibilidade de transferência do risco, associada as variações dos preços de hedgers para especuladores.

O risco do preço, que será fundamentalmente discutido neste trabalho, advém das oscilações nos preços das mercadorias a serem comercializadas no período pós colheita, e a depender das variações, o produtor pode não cobrir os seus custos de produção e consequentemente ficar inadimplente com seus credores. Nesse contexto para se defender dos riscos de preço, a cadeia produtiva poderá recorrer 
para os instrumentos dos derivativos para a proteção contra o "hedge" de suas atividades (RODRIGUES e FILHO, 2015). A partir disto, obteremos enfoque nas operações do mercado futuro que possuem o objeto do estudo, os contratos de café arábica no Brasil.

\section{Mercado Futuro}

Os Mercados futuros possuem uma organização com o intuito de estabelecer contratos futuros orientados por bolsas de valores, que buscam construir procedimentos e normas para a sua comercialização no mercado. Variações dos preços dos ativos transacionados podem ocasionar danos no mercado. Esta oscilação leva os agentes a buscarem algo que protejam seus investimentos dos riscos ou mesmo que diminuam esse potencial do risco, no caso dos mercados futuros, uma das alternativas está voltada para a utilização dos derivativos. (BITENCOURT, 2007).

A partir dessa ótica, existem três tipos de agentes que participam do mercado futuro sendo estes: os hedgers, arbitradores e especuladores. Para Hull (1994), os hedgers são os agentes que encaram o risco associado ao preço de um ativo e que utilizam o mercado futuro como uma estratégia para conseguir a sua eliminação ou pelo menos uma amenização.

Quanto ao mercado futuro de commodities, Rodrigues e Filho (2015) discutem que os preços futuros e à vista no mercado são determinados pelos seguintes tipos de participantes: produtores, consumidores, especuladores e governo. Os produtores geralmente tomam posições futuras a curto prazo contra o declínio dos preços. Os consumidores tomam posições futuras a longo prazo para se proteger contra o aumento nos preços. Os especuladores estão presentes no mercado à vista e futuro com o propósito de obter lucros. O governo assume um papel importante ao desenvolver programas de suporte aos produtores, e como interventor em caso de grandes oscilações dos preços das commodities (RODRIGUES e FILHO, 2015).

Os derivativos do café no Brasil são negociados na B3 e abarcam a variedade arábica. Estes contratos futuros e de opções são sobre o preço dessa variedade de café. Sendo estes dois tipos de contratos padronizados, de acordo com as normas e especificações da Bolsa de Valores. No contrato futuro do café a unidade mínima de

6Hedge: É um mecanismo que tem como objetivo proteger as operações financeiras com exposição a grandes variações de preços, protegendo o investidor do chamado risco de mercado, ou seja, do risco de exposição a variações ou volatilidade de determinados ativos (FARIAS, 2011). 
negociação equivale a 100 sacas de $60 \mathrm{~kg}$, cotados em dólar por saca, sendo a entrega realizada em portos e armazéns credenciados, que podem se localizar nos estados de Minas Gerais, Paraná e São Paulo (GILSON e KRAAKMAN, 2014).

\section{Eficiência de Mercado}

O conceito de eficiência de mercado possui origem na teoria econômica, tendo em vista que busca entender os fatores que influenciam as decisões que possibilitam otimizar o mercado, ou seja, torná-lo em equilíbrio e por consequência eficiente. Segundo esse conceito, a eficiência requer que uma atividade seja conduzida a um nível em que o custo marginal seja igual ao seu benefício marginal. Nesse contexto a hipótese de mercados eficientes pode ser estendida a partir do pressuposto que os títulos (ações, commodities, etc.) buscam estar sempre em equilíbrio, ou seja, ter um preço justo e que reflete as informações disponíveis dos contratos negociados (WESTON e BRIGHAM, 2000).

Vários estudos relatam que a HEM (HIPÓTESE DA EFICIÊNCIA DE MERCADO) foi originalmente concebida por Fama (1970), segundo o qual, em um mercado eficiente, os preços dos títulos sempre refletem toda informação disponível, e a única mudança que pode ocorrer resulta de nova informação. Nesse sentido, destacam que a eficiência dos mercados futuros tem confiado na racionalidade dos agentes envolvidos nas compras e vendas dos contratos (players) do mercado financeiro e na HEM.

O estudo de Fama (1970) relata ainda que existem três condições suficientes para que a HEM seja observada, primeiro não deve haver custos de transação nas negociações dos títulos; segundo, as informações devem ser disponibilizadas sem a inclusão de custos para os agentes do mercado; e terceiro, deve existir uma concordância geral nas expectativas dos investidores, quanto aos efeitos das informações sobre os preços atuais e futuros dos títulos. Nesse sentido, destaca, ainda, três formas de avaliação da eficiência:

- Fraca: Onde as informações dos preços passados não devem auxiliar os agentes a obterem retornos anormais no mercado;

-Semiforte: Os investidores não podem obter retornos anormais com base nas informações públicas, pois os preços se ajustam de forma imediata às novas informações disponíveis no mercado; 
- Forte: Os investidores não poderiam obter retornos anormais, mesmo que utilizem informações confidenciais/privilegiadas ainda não publicadas, já que o ajuste dos preços no mercado é instantâneo.

Nesse sentido, entende-se que um mercado é considerado eficiente, quando a HEM parte da suposição de que os agentes do mercado futuro são racionais, são neutros ao risco e, portanto, os preços futuros não contemplam prêmio ao risco. A eficiência de mercado assume, ainda, que, na data de vencimento de um contrato, os preços à vista (spot) e futuro deverão ser convergentes. Com isso, acredita-se que os preços futuros no período corrente podem ser preditores não viesados dos preços à vista esperados para o futuro. Desta maneira, os mercados eficientes não permitem aos investidores obter retornos acima da média sem recorrer a determinado grau de aceitação de riscos. Satisfazendo essas condições, a forma fraca de eficiência pressupõe que os preços futuros correntes são preditores/previsores não viesados dos preços à vista, esperados para o futuro para um determinado título (ARBEX e ROTARI, 2000).

\section{REVISÃO DE LITERATURA}

Quando busca-se compreender a dinâmica de um mercado eficiente, é necessário recorrer aos trabalhos que esclareceram esse processo como Samuelson (1965) que indicou a hipótese de mercados eficientes por meio da precificação temporal das commodities estocáveis, e estabeleceu que um mercado eficiente, seria aquele cujo dada as informações de mercado e expectativas dos agentes, as mudanças nos preços não deveriam ser previsíveis no mercado, tendo em vista que as informações de todos os agentes do mercado são incorporadas.

A partir disso, alguns trabalhos como o de Sabuhoro e Larue (1997) testaram a hipótese de eficiência de mercado para o mercado futuro de café e cacau usando dados diários para contratos com prazo de 2 e 6 meses. A primeira condição estabelecida é que os preços futuros e preço físico (spot) sejam cointegrados, está eficiência da hipótese é testada, verificando se o preço futuro é um estimador imparcial do correspondente preço spot futuro. Os resultados não são consistentes em todas as abordagens, eles fracamente favorecem a eficiência do mercado. $O$ teste de Engle-Granger apoiou a hipótese de cointegração para três dos quatro casos analisados. O procedimento Johansen e Juselius foi ainda favorável, pois não conseguiu rejeitar a cointegração em todos casos. Nesse sentido a evidência 
empírica tende a apoiar a afirmação que os mercados não são sistematicamente tendenciosos e consequentemente possuem uma fraca eficiência (SABUHRO e LARUE, 1997).

Bressan e Leite (2001) testaram a eficiência do mercado futuro de café brasileiro, a partir da previsão de preços dos contratos futuros de café, baseando-se nos dados de contratos negociados entre março de 1992 a março de 1998. Verificaram que houve autocorrelação nas séries de café no mercado futuro da B3, a partir de correlogramas com até cinco defasagens e estatística $Q$ de Ljung e Box e utilizaram o modelo de eficiência de previsão baseado em Nordhaus (1987), baseado na hipótese das expectativas racionais. Conduzidos esses testes para os 31 contratos analisados, destacaram que 42\% dos contratos apresentaram evidências de não eficiência. Destacou-se que não houve indícios de ineficiência, pois os coeficientes de autocorrelação foram estatisticamente iguais a zero. Concluíram que os contratos de café negociados foram eficientes no período analisado, ou seja, é possível averiguar que o mercado de café é eficiente ao adaptar suas cotações aos novos fluxos de informações disponíveis. (BRESSAN e LEITE, 2001).

O estudo de Amado e Carmona (2004) tinha como escopo analisar a existência ou não de uma eficiência do mercado futuro de commodities no Brasil, como base empregaram os contratos futuros de café que foram comercializados B3 no intercalar de 1995 a 2003. Nesse contexto, utilizaram o arcabouço econométrico das series temporais, sendo possibilitado a estimação e identificação das series, resultando na descoberta da integração das series. Os indicativos recomendam que o preço futuro de café é um estimador sem viés do preço físico, ou seja, pode-se perceber que existe uma eficiência de mercado nos contratos de café negociados na bolsa de valores de São Paulo.

Cruz e Silveira (2007) analisaram os contratos de café negociados B3 e na Bolsa de Valores de Nova York (NYBOT) e na Bolsa de valores Europeia EURONEXT- LIFFE. Os autores possuíam como escopo investigar a eficiência desses mercados no período de janeiro de 2002 a dezembro de 2006, aplicando testes de raízes unitárias, avaliando também se os preços futuros de (primeiro vencimento) possuem cointegração, e ainda se há uma relação de causalidade no sentido de Granger, e se as series podem ser considerados fracamente e/ou fortemente exógenas. Os resultados indicaram por meio dos testes que as series de preços futuros do café da B3, LIFFE e NYBOT possuem integração de ordem um, 
sendo possível avaliar que tais mercados são eficientes, uma vez que a series de retorno seguem um random walk ${ }^{7}$. Por conseguinte, avaliou-se que as series de preços futuros na B3 e NYBOT são cointegrados e causam, no sentido de Granger, os retornos nos demais mercados. Apenas os retornos na NYBOT são considerados fracamente exógenos (CRUZ e SILVEIRA, 2007).

Menegário et al. (2014) investigaram por meio da comparação da eficiência fraca entre o mercado futuro de café brasileiro e americano, de modo a identificar o processo de descoberta de preços mais robusto para a safra de café do Brasil. Estabeleceu a base do seu estudo com relação a eficiência fraca de mercado. Nesse sentido, avaliou a eficiência fraca dos mercados futuros de café arábica, na B3 e ICE, em relação a três mercados à vista, representativos da produção brasileira em diversas regiões, Franca (SP), Guaxupé (MG) e Vitória da Conquista (BA), no período de dezembro de 2008 a outubro de 2010. Para as séries dos preços da B3 e dos mercados à vista de Franca (SP), Guaxupé (MG) e Vitória da Conquista (BA), constatou-se que o mercado físico acompanha o futuro. Sendo que na maior parte do período analisado, a base, diferencial entre o preço físico e o futuro, permaneceu negativa. Os resultados apontaram para a rejeição da hipótese nula de ausência de vetor de cointegração entre o preço futuro da B3 e o preço físico nas três localidades consideradas. Os resultados evidenciaram a ocorrência da forma fraca de eficiência de mercado, sendo os preços futuros de café da B3 estimadores não viesados dos preços à vista para as três localidades analisadas. Não se obtém o mesmo resultado para a ICE. (MENEGÁRIO et. al., 2014).

A partir do arcabouço teórico metodológico discutido anteriormente é possível verificar que o principal objetivo dos estudos apresentados, foi analisar o grau de eficiência das commodities agropecuárias e se os preços físicos e futuros possuem uma relação de longo prazo, de maneira que possibilite estabelecer uma expectativa para compreender o comportamento do mercado e principalmente dos fatores que 0 tornam eficiente, levando em consideração os fatores que ocasionam as oscilações de preços, para que seja possível auxiliar os tomadores de decisões (Hedgers e especuladores) de forma eficiente nas melhores decisões nos piores cenários.

${ }^{7}$ Random Walk: $O$ modelo pressupõe que não existe diferença entre a distribuição de retornos condicionada a uma dada estrutura de informação e a distribuição incondicional de retornos, requerendo assim que todos os parâmetros da distribuição sejas os menos, com ou sem a estrutura de informação. Bitencourt (2007). 


\section{METODOLOGIA}

Neste trabalho será utilizado a técnica de Regressão quantílica, que possibilitará analisar a associação contemporânea entre a variável resposta (preço físico) com as variáveis explicativas (preço futuro) nos diversos quantis da distribuição condicional. Os dados utilizados foram obtidos junto à B3, para os preços futuros, e junto ao CEPEA (Centro de Estudos Avançados em Economia Aplicada) da ESALQ (Escola Superior de Agricultura "Luiz de Queiroz") da USP, para os preços à vista para a região noroeste do Paraná. O período analisado foi de 02/01/2007 a 28/12/2017, desconsiderando feriados ocorridos, a nível nacional que afetam as operações da B3 no período por não haver pregão em feriados o que totalizou 2480 observações.

As séries de preços diários, utilizadas neste trabalho, referem-se ao café arábica com vencimento em março de cada ano correspondente e estão em dólares, tanto os preços físicos obtidos no CEPEA como as cotações da B3, tendo em vista que as cotações são fechadas em relação a moeda norte-americana, sendo obtidas através do banco de dados da B3 em 2018. Devido aos feriados ou simplesmente à ausência de cotação, as séries diárias de preços à vista e as cotações dos contratos futuros de café arábica negociados na B3 foram compatibilizadas, mantendo-se somente os dias comuns a todas as séries.

\section{Modelo de Regressão Quantílica}

Tendo em vista que o modelo econométrico utilizado pela revisão da literatura girava em torno do MQO, modelos autorregressivos ou de Máxima Verossimilhança, este trabalho utiliza a técnica de Regressão Quantílica, e que será o próprio diferencial do trabalho, pois por meio deste método será possível obter noções mais completas da eficiência dos contratos de café arábica na B3, sendo mais provável investigar como cada quantil responde, ao invés de ter somente uma reta de regressão para o caso da média.

Silva e Junior (2006) destacam que a regressão quantílica pode ser vista como uma extensão natural dos quantis amostrais para o caso de um modelo linear $Y_{t}=X_{t} \beta+\varepsilon_{t}$, o qual assume a seguinte forma:

$$
\operatorname{Minn}^{-1}\left\{\sum_{t \in\left[t: Y_{t} \geq X_{t} \beta\right\}} \theta\left|Y_{t}-X_{t} B\right|+\sum_{t \in\left[Y_{t}<X_{t} \beta\right\}}(1-\theta)\left|Y_{t}-X_{t} B\right|\right.
$$


(1)

$$
=\operatorname{Min} n^{-1} \sum_{i=1}^{n} \rho_{\theta}\left(Y_{t}-X_{t} \beta\right)
$$

Em que o $\rho$ é a função "check" definida por :

$\rho_{\theta}(U)=\left\{\begin{array}{cc}\theta u, & u, \geq 0 \\ (\theta-1) u, & u,<0\end{array}\right.$

Onde a função $\rho \theta$ multiplica os resíduos por $\theta$ se eles forem não-negativos $\mathrm{e}$ por $(\theta-1)$ caso contrário, para que desta forma sejam tratados assimetricamente. Além da técnica da regressão quantílica utilizar-se-á o mecanismo de correção de erros para regressão de cada quantil, a partir do software Gretl para obter os resultados sobre raiz unitária, cointegração e regressão quantílica,

No modelo de regressão expresso pela equação (1), a condição para um mercado futuro eficiente e seus preços sejam estimadores não viesados dos preços do mercado à vista ocorre quando os parâmetros $Y$ e $X$ não forem significativamente diferentes de 0 e 1, respectivamente, e que os resíduos sejam de ruído branco. Ressalta-se que o $\beta_{0}$ é o coeficiente linear que irá representar o prêmio risco do investimento e $\circ \beta_{1} \circ$ coeficiente angular que irá relatar a taxa ótima do hedge. $O$ coeficiente de correlação entre as variações dos preços à vista e futuro ao quadrado $R^{2}$, encontrado no modelo irá revelar a eficiência do hedge. Desta forma, quanto maior o valor do coeficiente, mais eficiente será a operação de hedge, já que as variações dos preços à vista serão bem explicadas pelas variações nos preços futuros, o que demonstra um menor risco de base.

Serão utilizados o teste de White para verificar se a regressão apresenta ou não a hipótese de normalidade, sua hipótese nula $\left(H_{0}\right)$ pressupõe uma não Heterocedasticidade dos dados e a hipótese alternativa $\left(H_{1}\right)$ implica uma Heterocedasticidade. Para verificar a presença de autocorrelação será utilizado o teste de Durbin-Watson para detectar a presença de autocorrelação (dependência) nos resíduos de uma análise de regressão. Este teste é baseado na suposição de que os erros no modelo de regressão são gerados por um processo autorregressivo de primeira ordem. (GREENE, 2012)

\section{RESULTADOS}

Nota-se ainda que ao longo dos anos aconteceram quatro picos de aumentos de preços. O primeiro a ser verificado foi um leve aumento na média dos preços ocorrido em 2007 mesmo em época de pré-crise que se alastrou em escala global está commodity continuou com um crescimento razoável, tendo em vista que é um 
produto de consumo diário e de baixo custo. O segundo pico e mais crescente aumento ocorreu entre o ano de 2009 se propagando até meados de 2011, isso aconteceu devido ao elevado aumento da demanda mundial de café e das condições climáticas favoráveis nas regiões produtoras que possibilitam uma floração atípica nos cafezais (CONAB, 2018).

Após esse aumento anormal nos preços, o próximo aumento incidiu na safra de 2013/2014 por causa de tratos culturais mais adequados, crescente aumento na utilização de irrigação, manejo de podas nos cafeeiros, adensamento das lavouras, plantio de variedades mais produtivas e melhores adaptadas, e por fim, a renovação constante dos cafezais. O último aumento na safra 2015/2016 foi brando, semelhante ao ocorrido em 2008, contudo foi o ano que bateu o recorde da produção nacional de café, devido a condições climáticas favoráveis aliadas ao ciclo de bienalidade positiva, o que favoreceu o desempenho das lavouras e justificam aumento da produtividade na maioria dos estados.

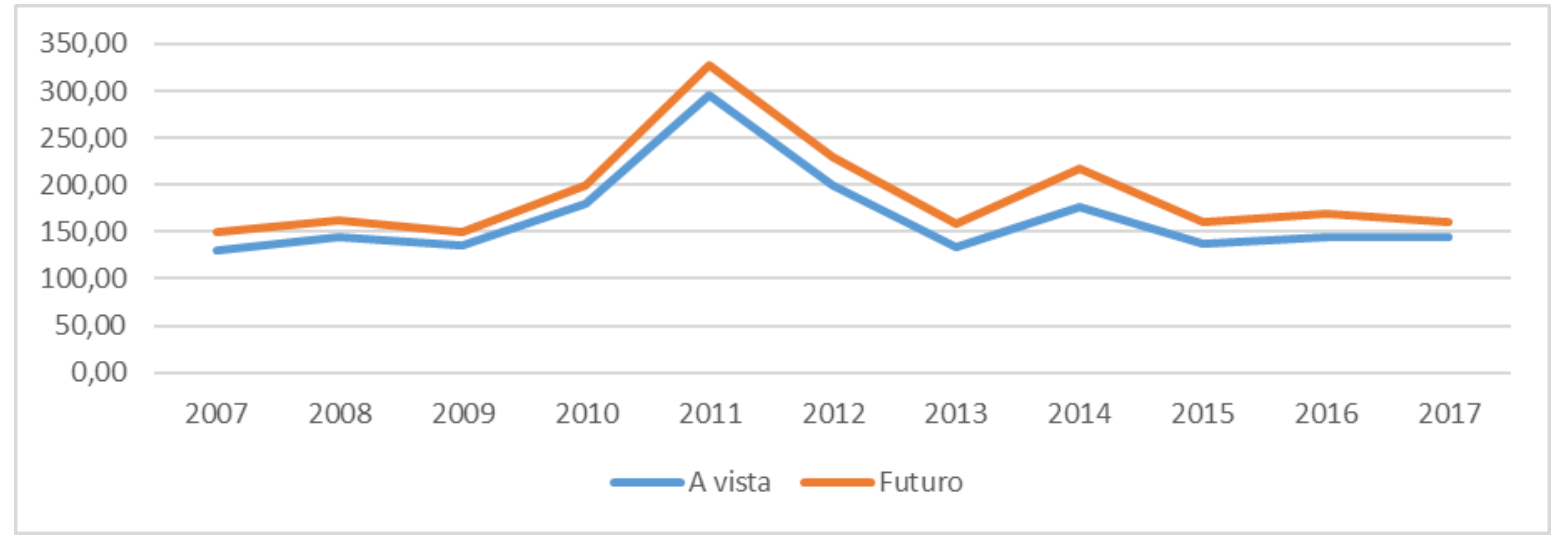

Figura 1.1 - Evolução média dos preços à vista e futuro de café arábica de 2007 a 2017.

Fonte: 1.1 Elaboração do autor, a partir de dados diários disponibilizados pela B3 e CEPEA-ESALQ

A figura 1.2 retrata a série temporal do preço à vista decomposto em seus quantis $0,05,0,25,0,50,0,75,0,95$. Analisando-os, pode-se perceber que os menores quantis $(0,05$ e 0,25$)$ são menos sensíveis aos aumentos dos preços nos anos 2008, 2014 e 2016, exceto no ano de 2011. 


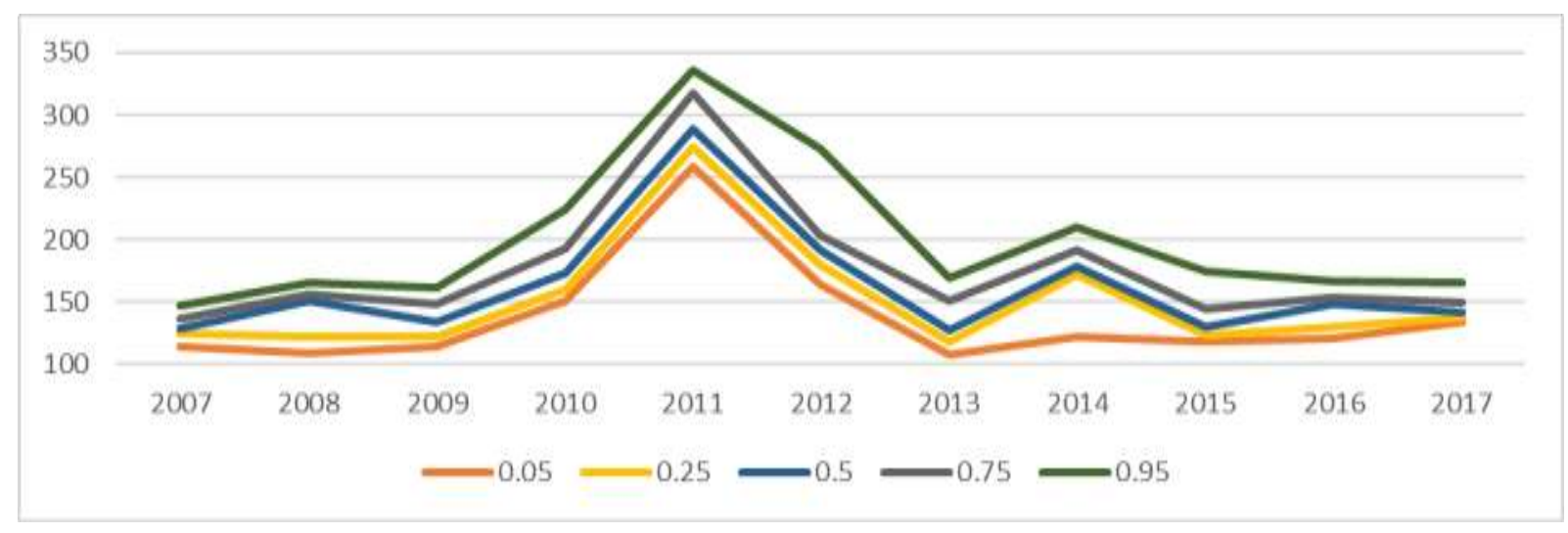

Figura 1.2 - Distribuição dos preços à vista e futuro por quantis de 2007 a 2017 Fonte: 1.2 Elaboração do autor, a partir de dados diários disponibilizados pela B3 e CEPEA-ESALQ

De forma a englobar a análise dos quantis dos preços em todos os anos do estudo, a Figura 1.3 revela a evolução dos preços médios cotados em cada quantil, a evolução dos preços ocorre de forma lenta e gradual não possuindo aumentos abruptos, isto é, não sendo influenciados por outliers. Nota-se ainda que os aumentos médios dos preços do café são referentes a expansão gradual do consumo interno como externo que impulsiona a produção, área plantada e colhida, assim como o desenvolvimento de técnicas que possibilitem o melhoramento genéticos das mudas de café no Brasil.

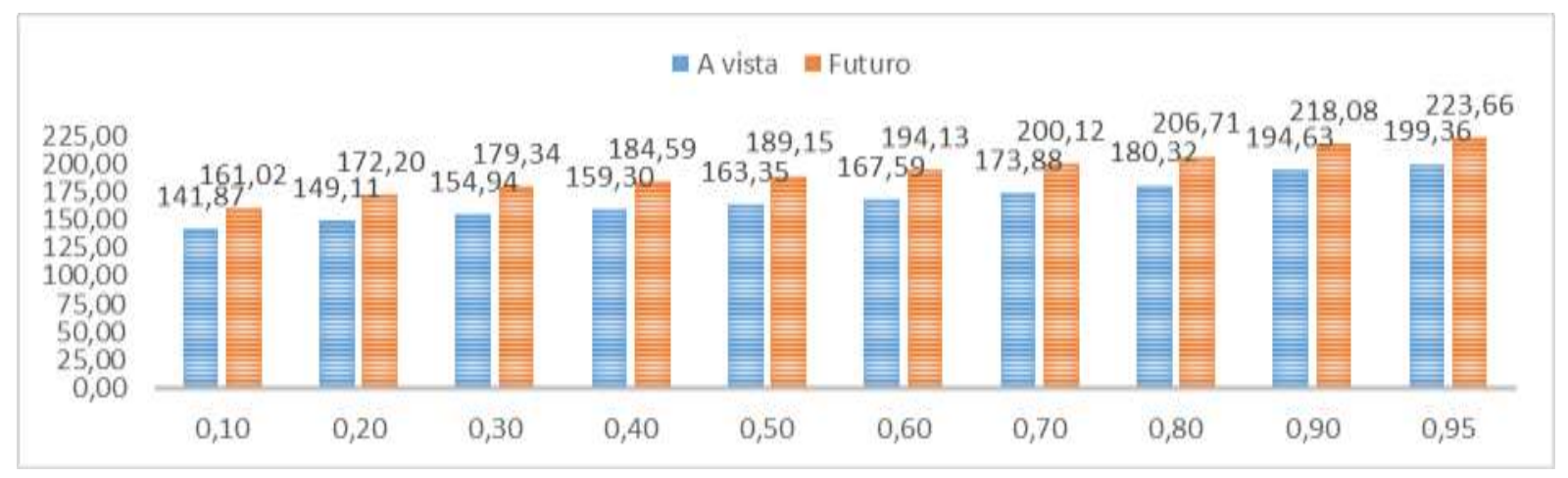

Figura 1.3 - Comparação entre os preços à vista e futuro distribuído em quantis, no período de 2007 a 2017.

Fonte: 1.3 Elaboração do autor, a partir de dados diários disponibilizados pela B3 e CEPEA-ESALQ

Para analisar se as séries temporais dos preços à vista e futuro possuem uma raiz unitária, optou-se por utilizar o teste ADF e para testar se a regressão entre os preços é uma regressão espúria foi aplicado o teste de Engle-Granger que verificam se os resíduos dessa regressão são estacionários (Tabela 1.2).

Os resultados para o teste ADF indicam com 1\% de significância que ambos os preços possuem uma raiz unitária, ou seja, não são estacionárias, porém ao se realizar o teste para as primeiras diferenças encontra-se que as séries são 
estacionárias, portanto são integradas de ordem 1, o mesmo resultado encontrado nos trabalhos de Cruz e Silveira (2007), e Amado e Carmona (2004).

Tendo em vista que o preço físico e futuro, são não estacionários e integrados de mesma ordem a próxima a etapa a ser cumprida será consiste em verificar se existe uma relação entre os preços da ESALQ e da B3, a partir do teste de EngleGranger. Para o teste Engle-Granger o p-valor obtido foi inferior a $1 \%$ de significância, indicando que as séries são cointegradas, não existindo uma relação espúria ao se modelar os preços à vista e futuro, assim como aconteceu nos trabalhos de Sabuhoro e Larue (1997); Amado e Carmona (2004); Cruz e Silveira (2007); Bitencourt (2007) Menegário et. al. (2014).

Com o objetivo de aplicar a regressão quantílica, a Tabela 1.3 verifica diante do teste de Engle-Granger se nos quantis a regressão é espúria. De acordo com o $p$-valor dos resultados a regressão não é espúria nos decis, indicando que os preços à vista e futuro caminham juntos.

Tabela 1.3 - Teste Engle-Granger para regressão em cada decil.

\begin{tabular}{cccccccccc}
\hline Tau & 0.10 & 0.20 & 0.30 & 0.40 & 0.50 & 0.60 & 0.70 & 0.80 & 0.90 \\
\hline p-valor & $<0,01^{*}$ & $<0,01^{*}$ & $<0,01^{*}$ & $<0,01^{*}$ & $<0,01^{*}$ & $<0,01^{*}$ & $<0,01^{*}$ & $<0,01^{*}$ & $<0,01^{*}$ \\
\hline
\end{tabular}

Fonte: Elaboração do autor a partir de dados diários disponibilizados pela B3 e CEPEA-ESALQ

Para analisar a taxa ótima e eficiência de mercado a Tabela 1.4 apresenta os resultados da aplicação da regressão de Cointegração e regressão quantílica com a indicação de coeficientes não significativos a $5 \%$.

Tabela 1.4 - Resultados da Regressão quantílica e de Cointegração, seguido do pseudo $\mathrm{R}^{2}$ e $\mathrm{R}^{2}$, respectivamente.

\begin{tabular}{ccccccccccc}
\hline Tau & 0,10 & 0,20 & 0,30 & 0,40 & 0,50 & 0,60 & 0,70 & 0,80 & 0,90 & MQO \\
\hline Const & $0,80^{*}$ & $-2,67$ & $-3,21$ & $-2,33$ & $-1,26^{*}$ & $0,06^{*}$ & 1,82 & $0,38^{*}$ & $-3,75$ & $-3,74$ \\
Preço futuro & 0,80 & 0,84 & 0,86 & 0,87 & 0,88 & 0,88 & 0,88 & 0,91 & 0,96 & 0,89 \\
Pseudo R ${ }^{2}$ & 0,70 & 0,73 & 0,75 & 0,77 & 0,78 & 0,79 & 0,81 & 0,83 & 0,85 & 0,96 \\
\hline * Significativo a 5\%. \\
Fonte: Elaboração do autor a partir de dados diários disponibilizados pela B3 e CEPEA-ESALQ
\end{tabular}

A regressão de cointegração estimou uma taxa ótima de 0,89 , próxima do valor unitário esperado, com eficiência de $96 \%\left(R^{2}\right)$ o que torna os investimentos no mercado futuro uma boa escolha para se maximizar a relação risco-retorno, entretanto o coeficiente estimado para o prêmio ao risco foi de $-3,74$, isto significa dizer que os hedgers conseguem repassar aos especuladores (amantes do risco), 
em média, a perda de $\bigcup \$ \$ 3,74$, independentemente do valor comprado no mercado futuro.

Essas análises são prejudicadas pelo fato do modelo de cointegração apresentar que os resíduos não são normalmente distribuídos, segundo o teste Jarque - Bera ( $p$-valor <0,01), heterocedásticos por meio do teste White ( $p$-valor $<0,01)$ e fortemente autocorrelacionados $(d=0,11)$. O que impossibilita a inferência realizada anteriormente, pois os testes t para os coeficientes não podem mais ser realizados, não se pode garantir que a variância estimada para os resíduos é mínima.

A regressão quantílica aparece para contornar esses problemas, pois não exige as suposições de normalidade e homocedasticidade. Podem-se interpretar os coeficientes estimados para a regressão em cada decil. Sobre o coeficiente estimado associado do prêmio ao risco, tem-se que para os decis 0,10, 0,50, 0,60 e 0,80 não foram significativos a $5 \%$, sendo um cenário perfeito para se aplicar 0 hedging por não se ter um risco associado ao investimento, enquanto que nos demais decis, exceto o 0,70 , o prêmio ao risco revelou um prejuízo para os especuladores. No decil 0,70 evidencia-se o cenário ideal para os especuladores, uma vez que é a única situação no qual se obtém um prêmio ao risco associado a uma taxa ótima e eficiência.

A partir das representações destacadas acima, salienta-se a partir da interpretação dos decis para o período estudado que a maioria dos contratos negociados com o vencimento em março obtiveram uma taxa ótima ou eficiência do hegde que possibilitou as negociações em um cenário com risco mínimo aos agentes que se propuseram a investir em um cenário de incerteza.

A Figura 1.4 representa graficamente a relação entre os coeficientes estimados da regressão em cada decil. A primeira região marcando os decis 0,20 , 0,30 e 0,40 refletem em um prêmio negativo, a próxima indicação mostra o prêmio ao risco negativo no decil 0,70 , enquanto que no decil 0,90 retorna a ser negativo. 


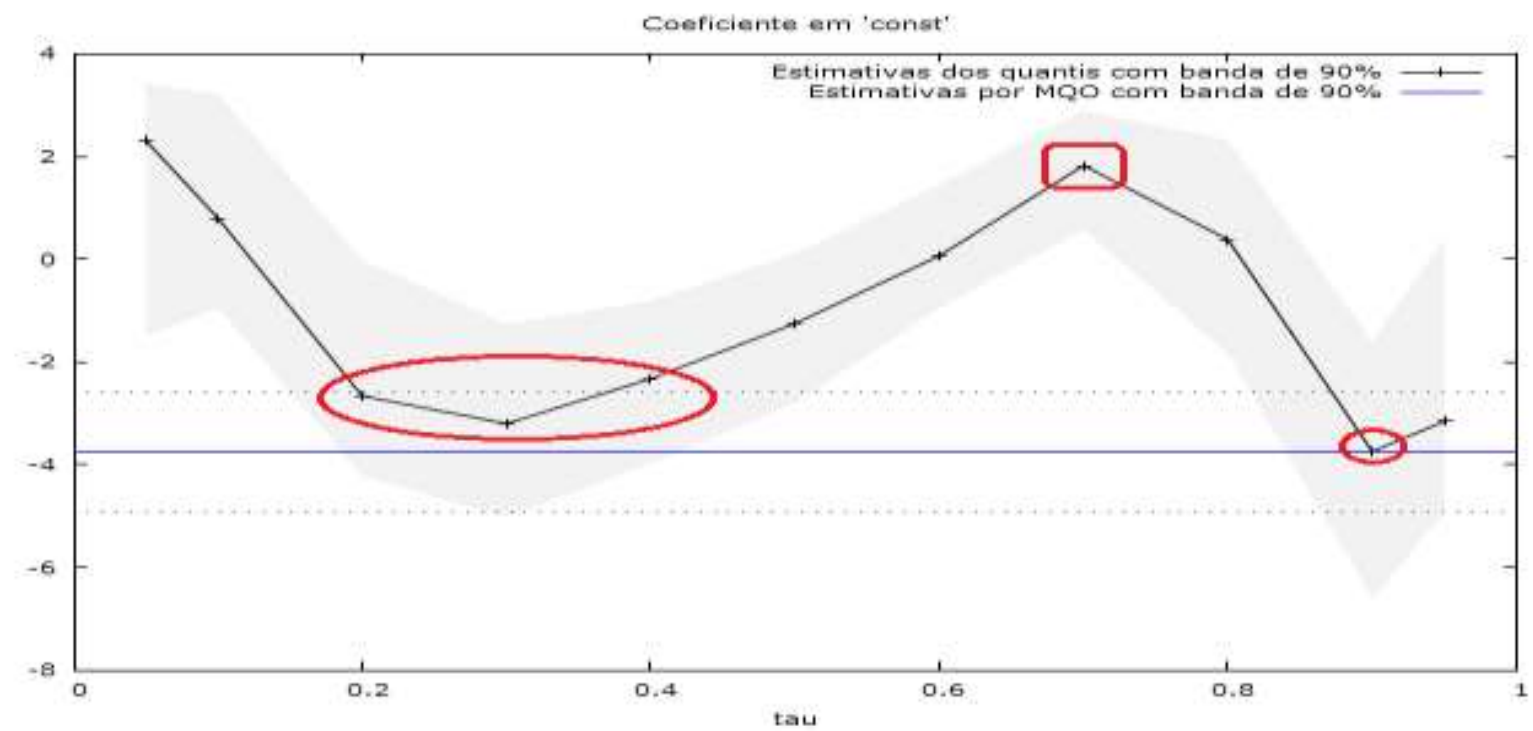

Figura 1.4 - Estimativa do prêmio ao risco para a regressão de cada decil.

Fonte: 1.4 Elaboração do autor a partir de dados diários disponibilizados pela B3 e CEPEA-ESALQ

A estimação pela regressão de cointegração (MQO) calcula de maneira estática um valor fixo para todos os preços, e na figura 1.4 percebe-se que a mesma só não se distancia das estimativas da regressão quantílica nos decis que foram negativos.

A taxa ótima aumenta gradativamente de decil em decil, mostrando que quanto maiores o nível de preços, mais provável será o alcance do valor unitário. A figura 1.5 apresenta a estimativa da taxa ótima entre os decis, comportando-se de forma crescente até o decil 0,70 e crescendo de forma abrupta até o 0,90. Dessa forma, a eficiência de mercado é mais forte nos preços mais elevados e moderadamente nos demais. Neste sentido, pode-se destacar que os agentes possuem maior "tranquilidade" em se arriscar em um cenário de preços elevados com retornos maiores do que com preços moderados e retornos/ prêmio risco baixo ou nulo. 


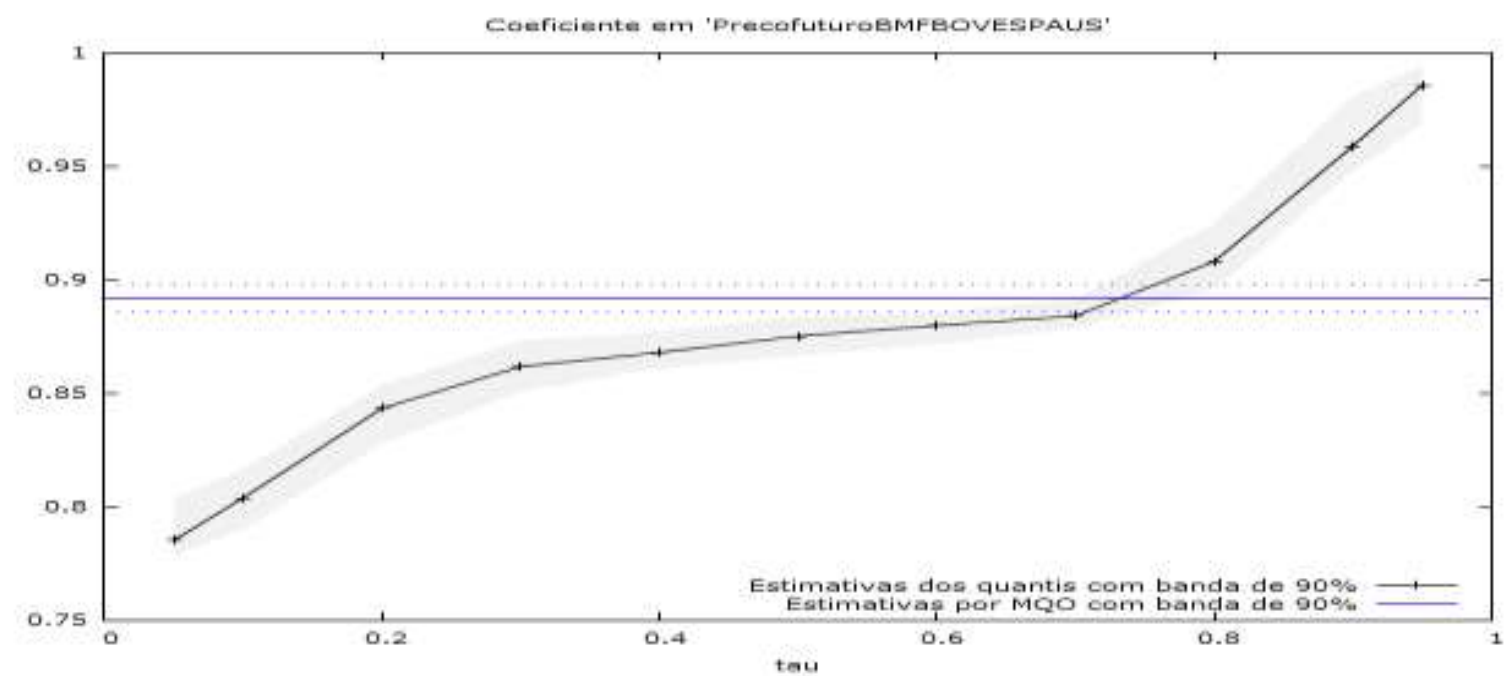

Figura 1.5 Estimativa da taxa ótima para a regressão de cada decil

Fonte: 1.5 Elaboração do autor, a partir de dados diários disponibilizados pela B3 e CEPEA-ESALQ.

A eficiência de mercado também aumenta a cada decil, com a situação ótima no decil 0,80 por não possuir prêmio ao risco e explicar cerca de $83 \%$ das variações dos preços à vista, portanto a operação de hedge deve ser aplicada a longo prazo na diversificação com maior investimento no preço futuro. A regressão de cointegração não consegue captar as variações da regressão quantílica, pois essa mostra a importância da eficiência em relação a magnitude dos preços.

A Figura 1.6 retrata as diferenças em se modelar pela regressão de cointegração e a regressão quantílica, ilustrando as retas estimadas para ambas possibilitando ver seu efeito individual. É perceptível que as regressões captam efeitos particulares, a regressão de cointegração por ser baseada na média dos preços capta os efeitos centrais dos dados, podendo ser influenciado por outliers, enquanto que a regressão quantílica consegue analisar os efeitos em cada quantil.

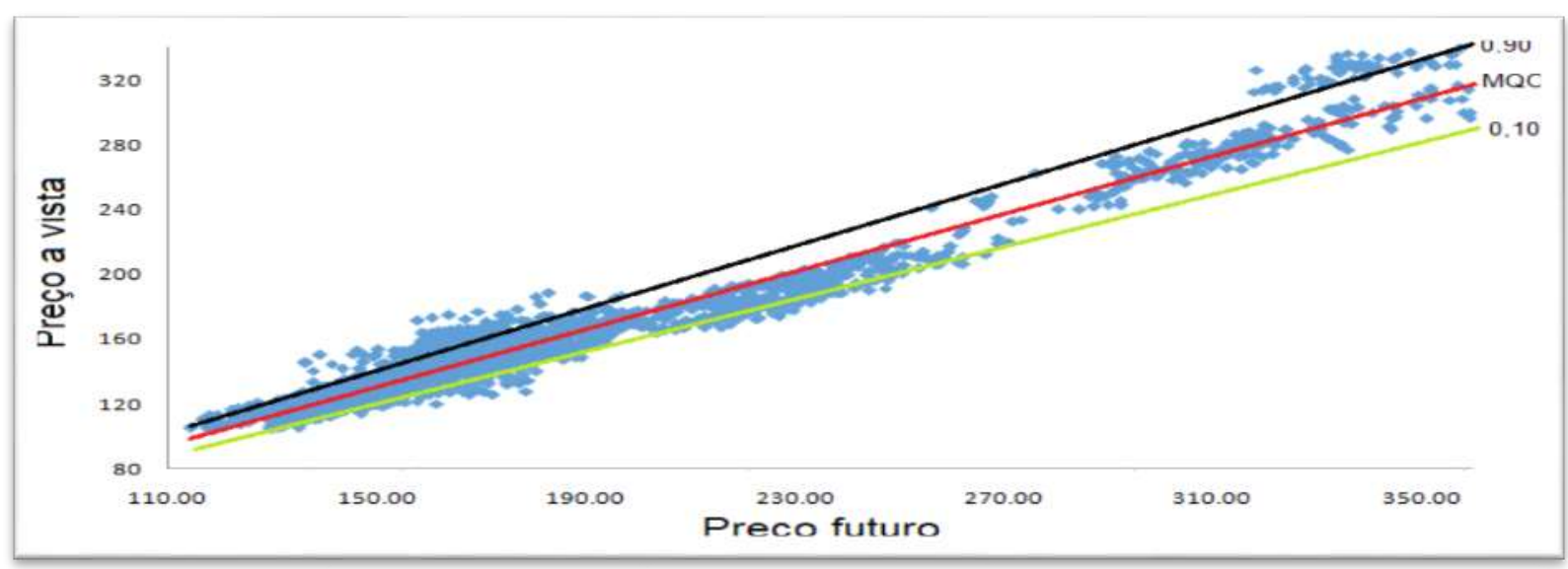

Figura 1.6- llustração das retas da regressão de cointegração e regressão quantílica para os decis 0,10 e 0,90.

Fonte: 1.6 Elaboração do autor, a partir de dados diários disponibilizados pela B3 e CEPEA-ESALQ 
Observe que a regressão para o decil 0,10 reflete nos menores preços cotados e a regressão para o decil 0,90 nos maiores preços. Desta forma, pode-se verificar quais os decis são mais significativos e em quais contratos os preços físicos foram mais representativos para estimar o preço futuro, sendo possível ainda a partir do método da regressão quantílica descobrir em quais períodos os preços promovem uma relação de cointegração evidente.

A Tabela 1.5 mostra os resultados para a construção do mecanismo de correção de erros para a regressão de cointegração e regressão quantílica, com o objetivo de se analisar os efeitos de curto prazo na eficiência do mercado.

Tabela 1.5 - Mecanismos de correção de erros para regressão de cointegração e regressão quantílica.

\begin{tabular}{crrrrrrrrrr}
\hline Tau & 0,10 & \multicolumn{1}{c}{0,20} & 0,30 & 0,40 & 0,50 & 0,60 & 0,70 & 0,80 & 0,90 & MQO \\
\hline Const & $-2,28$ & $-1,54$ & $-0,91$ & $-0,42$ & $0,01^{* *}$ & 0,47 & 0,97 & 1,52 & 2,36 & $-0,01$ \\
$\Delta$ Preço futuro & 0,55 & 0,55 & 0,56 & 0,55 & 0,56 & 0,54 & 0,52 & 0,49 & 0,43 & 0,48 \\
Resíduos $t_{-1}$ & $-0,05$ & $-0,02$ & $-0,02$ & $-0,02$ & $-0,03$ & $-0,03$ & $-0,03$ & $-0,04$ & $-0,05$ & $-0,04$ \\
Pseudo R ${ }^{2}$ & 0,21 & 0,20 & 0,19 & 0,18 & 0,18 & 0,18 & 0,17 & 0,18 & 0,19 & 0,32 \\
\hline
\end{tabular}

**Significativo a $5 \%$.

Fonte: Elaborado pelo autor, a partir de dados diários disponibilizados pela B3 e CEPEA-ESALQ.

O mecanismo de correção de erros para a regressão quantílica apresenta praticamente a mesma eficiência de mercado para todos os decis, estando entorno de $18 \%$ a $21 \%$. Note que no caso do curto prazo a taxa ótima e eficiência de mercado caem bruscamente em comparação ao longo prazo, portanto para diminuir seu risco é mais interessante o investimento na compra do café a vista. O modelo de regressão de cointegração do MQO alcançou má eficiência de mercado em curto prazo maior com 32\%, mesmo assim bem abaixo em relação ao longo prazo.

Pode-se observar o comportamento das estimativas dos prêmios ao risco a partir da figura 1.7, onde apenas na mediana (decil 0,05 ) e na cointegração que não existem o prêmio ao risco, sendo presente na regressão dos decis $0,10,0,20,0,30$, e 0,40 com sinal negativo, apesar de mostrarem maiores valores para taxa ótima em comparação com os decis $0,60,0,70,0,80,0,90$, mas possuem prêmio ao risco com sinal positivo, sendo que apenas quando os preços aumentam o risco assumido pelos especuladores é recompensado. Podemos dizer que risco não sistemático que os agentes assumiriam ao negociar os contratos de café arábica possibilitaram um prêmio risco positivo em algumas estimativas, sendo mais representativo esse "lucro" quando as flutuações de preços no mercado são mais intensas como no período de 2009 a 2011 que obteve o maior nível de preços do estudo. 




Figura 1.7 - Representação gráfica das estimativas do prêmio ao risco entre os quantis.

Fonte: 1.7 Elaborado pelo autor, a partir de dados diários disponibilizados pela B3 e CEPEA-ESALQ.

Isso evidencia para os hedgers a não indicação no curto prazo para investir no mercado futuro enquanto os preços à vista estão baixos ou altos, apenas quando estiverem em um valor mediano, no qual possibilitarão retornos mais significativos.

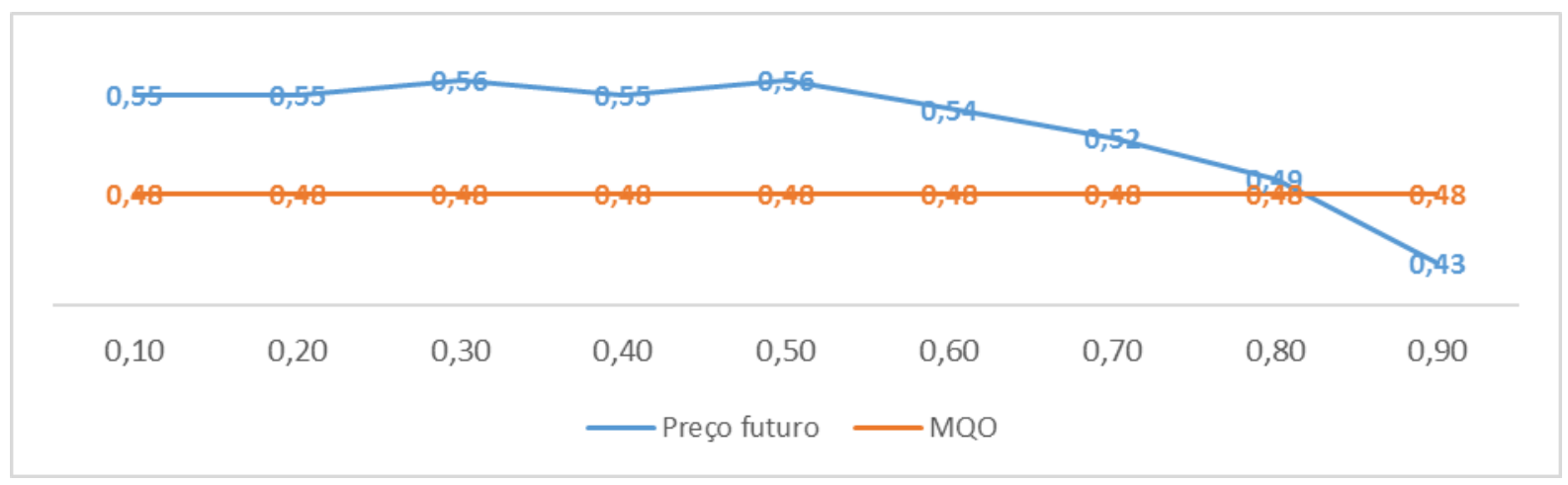

Fonte: 1.8 Elaborado pelo autor, a partir de dados diários disponibilizados pela B3 e CEPEA-ESALQ. Figura 1.8 - Representação gráfica da estimativa da taxa ótima entre os Quantis

Em relação a a taxa ótima obtemos a representação acima sobre comportamento entre os decis, a mesma se mantém estável até a mediana, quando os preços a ultrapassam essa taxa se torna decrescente, caindo de 0,56 na mediana e chegando a 0,43 no decil 0,90. O mercado futuro investiga essa taxa otima que é encontrrada a partir do coeficiente de correlação $R^{2}$ e vai verificar o nivel de eficiencia que dado mercado futuro proporciona com base nos preços fisico e futuro. Neste sentido com base nessa taxa otima que será possivel verificar o grau de eficiencia que o mercado produz em dado periodo. 


\section{Considerações Finais}

Este estudo teve por intuito testar a forma fraca de eficiência do mercado futuro brasileiro dos contratos de café arábica negociados na B3 com vencimento em março, utilizando a técnica da regressão quantílica, para verificar se os preços futuros correntes são estimadores não viesados dos preços à vista esperados no período compreendido entre janeiro de 2007 e dezembro de 2017.

Para alcançar os objetivos foram utilizadas as técnicas da regressão quantílica, testes de raízes unitárias (DICKEY-FULLER), e modelo de correção de erros (MCE), para verificar se os preços físicos do CEPEA-ESALQ e futuros da B3 dos contratos de café arábica são estacionários, se possuem uma cointegração e por fim se caminham juntos no longo prazo sem desequilíbrios.

Os resultados para o teste ADF indicaram com $1 \%$ de significância que ambos os preços possuem uma raiz unitária, ou seja, não são estacionárias, porém ao se realizar o teste para as primeiras diferenças encontrou-se que as séries são estacionárias, portanto são integradas de ordem 1, corroborando os estudos de Cruz e Silveira (2007), e Amado e Carmona (2004)

Verificou-se diante do teste de Engle-Granger se a regressão era espúria nos decis e de acordo com o $p$-valor dos resultados a regressão não é espúria, indicando que os preços à vista e futuro caminham juntos, ou seja, possuem uma relação de longo prazo. Tal fato era esperado, tendo em vista que os preços futuros da B3 são baseados na mesma commodity, o café arábica.

A regressão de cointegração apresentou uma taxa ótima de hedge de 0,89, próxima do valor unitário esperado, com eficiência de $96 \%\left(R^{2}\right)$ o que torna os investimentos no mercado futuro uma boa escolha para se maximizar a relação risco-retorno, Contudo o coeficiente linear que representa o valor do prêmio ao risco foi de $-3,74$, isto evidencia que os hedgers conseguem repassar aos especuladores, em média, a perda de $\bigcup \$ \$ 3,74$, deste modo percebe-se que os contratos negociados no período não propiciaram uma taxa ótima de hedge para garantir um prêmio risco satisfatório aos investidores dispostos a enfrentar o risco.

O mecanismo de correção de erros para a regressão quantílica apresentou praticamente a mesma eficiência de mercado para todos os decis, estando entorno de $18 \%$ a $21 \%$. Note que no caso do curto prazo a taxa ótima e eficiência de mercado caem bruscamente em comparação ao longo prazo, portanto para diminuir seu risco é mais interessante o investimento na compra do café a vista. O modelo de 
regressão de cointegração alcançou má eficiência de mercado em curto prazo maior com 32\%, mesmo assim bem abaixo em relação ao longo prazo.

Nessa perspectiva, evidenciou-se o papel dos preços físicos na formação dos preços futuros. Dessa forma, foi possível evidenciar que os preços físicos possuem relação com os preços futuros, sendo estes estimadores dos preços físicos, mas não podemos afirmar que são estimadores não viesados, tendo em vista utilizou-se apenas uma base de dados para investigar os preços físicos, podendo ocasionar um viés de seleção de amostra. Além desse fator foi possível perceber a presença de prêmio risco na maioria dos contratos analisados, contudo deve-se atentar que este segue tendência positiva para compensar o risco quando apenas quando os preços das ações estão mais elevados. Assim, destaca-se que para os hedges não haveria uma indicação para investir no curto prazo no mercado futuro, pois com valores de ações medianos o prêmio risco não irá compensar esses investimentos, podendo ocasionar prejuízos.

Destaca-se ainda que o prêmio risco advindo das negociações do contrato de café arábica na B3 foi mais representativo e robusto nos períodos em que as oscilações de preços alcançaram o seu auge, assim o risco assumido pelos especuladores possibilita um prêmio risco positivo em algumas estimativas, sendo mais intenso no período de 2009 a 2011 que obteve o maior nível de preços do estudo.

A taxa ótima aumentou gradativamente de decil em decil, mostrando que quanto maiores o nível de preços, mais provável será o alcance do valor unitário, além disso a taxa ótima se mantéve estável até a mediana, quando os preços a ultrapassam essa taxa se torna decrescente, caindo de 0,56 na mediana e chegando a 0,43 no decil 0,90 .

A partir dessa otica foi possivel estabelecer com base nos testes empregados e no modelo de regressão quantilica, que o mercado futuro de café arabica apresentou eficiencia fraca como preconizado por Fama (1970), em alguns periodos apresentou eficiencia com pagamento de prêmio risco e em outros quantis houve eficiência sem o pagamento de prêmio de risco, ocasionando em prejuizos ou ganhos nulos.

Nesse contexto, este estudo alcançou os objetivos propostos, a partir da analise da eficiencia do mercado e dos preços fisicos e futuros da commodity café na bolsa de valores de São Paulo. Contudo, este trabalho como outros que buscaram comprovar a eficiencia de mercado não são univocos e podem ser 
interpretados segundo oticas diferentes e metodologias distintas que possibitam no caso do mercado futuro divergências conceituais, e por esse motivo o estudo da eficiencia de mercado não termina, tendo em vista a suas diversas oticas e modelos de interpretação.

\section{REFERÊNCIAS}

AMADO, Carlos F. Pedrosa; CARMONA, Charles U. de Montreuil. Eficiência dos Mercados Futuros: um estudo utilizando teste de cointegração para commodities agrícolas. In: XXVII EANPAD, 27. 2003, Atibaia. Anais... Atibaia: 2003.

AMADO, Carlos F. Pedrosa; CARMONA, Charles U. de Montreuil. Análise da Eficiência dos Mercados Futuros Agrícolas Brasileiros: uma análise da eficiência dos mercados futuros agrícolas brasileiros. In: IV Encontro Brasileiro de Finanças, 4. 2004, Rio de Janeiro. Anais... Rio de Janeiro: 2004. Disponível em: <http:// bibliotecadigital.fgv.br/ocs/index.php/ebf/4EBF/paper/view/1522/641>. Acesso em: 08 jan. 2018.

ARBEX, M. A; ROTATORI, W. L. Eficiência em mercados futuros, prêmios de risco e bandas de câmbio no Brasil. Revista Estudos Econômicos, São Paulo, V. 30, N. 4, p. 525-547, out/dez 2000. Disponível em:< file:///C:/Users/Windows\%207\%20x64/Downloads/117667-Texto\%20do\%20artigo216956-1-10-20160715.pdf>. Acesso em 20 de fev. de 2019.

BRESsAN, A. A. e LEITE, C. A. M. Eficiência do Mercado Futuro de Café no Brasil, Reuna 6 (1), 11-32. 2001. Disponível em: < http://www.scielo.br/pdf/rbe/v70n2/0034-7140-rbe-70-02-0245.pdf>. Acesso em 18 de Fev. de 2019.

BITENCOURT, W. A. Ensaios empíricos sobre a eficiência do mercado futuro de café. Dissertação (Mestrado em Administração) - Universidade Federal de Lavras, Lavras, 2007. Disponível em: < http://repositorio.ufla.br/bitstream/1/2626/1/DISSERTAC̣ÃO Ensaios\%20empíricos\% 20sobre\%20a\%20eficiência\%20do\%20mercado\%20futuro\%20de\%20café.PDF>. Acesso em 20 de fev. 2019.

BMEF. Bolsa de Mercadorias e Futuros. Disponível em: <http://www.bmf.com.br>. Acesso em: mar. 2018.

CONAB. Acompanhamento da Safra Brasileira: Café. V. 1, no. 1, 2018 quadrimestral. Disponível em: <https://www.conab.gov.br/info-agro/safras/cafe>. Acesso em: 30 fev. 2019.

CEPEA, Centro de Estudos Avançados Economia Aplicada (ESALQ/USP). Disponível em: <https://www.cepea.esalq.usp.br/br/categoria/informativo-de-cafearabica.aspx> . Acesso: 05 de fev. 2018. 
CRUZ JR., J. C; SILVEIRA, R. L. F. (2007), Análise de Eficiência, Cointegração e Exogeneidade nos Mercados Futuros de Café na BM\&FBOVESPA, nyb ot e liffe', XLV Congresso Brasileiro de Economia e Sociologia Rural. Disponível em:< http://www.scielo.br/scielo.php?script=sci arttext\&pid=S1413-80502015000200349>. Acesso em 30 de jan. de 2019.

DICKEY, D.; FULLER, W. Distribution of the estimators for autoregressive time series with a unit root. Journal of the American Statistical Association, n. 366, v.74, p. 427-431, 1979.

EMBRAPA. Empresa Brasileira de Pesquisa Agropecuária. Disponível em: <http://www.embrapa.gov.br >. Acesso em: fev. 2019.

FAMA, Eugene F. Efficient Capital Markets: A Review of Theory and Empirical Work. The Journal of Finance, New York, v. 25, n. 2, p. 383-417, may 1970. Disponível em:

$<$ http://finance.martinsewell.com/stylizedfacts/volatility/Fama1970.pdf >. Acesso em: 02 jan. 2019.

FARIAS, A.T. Mercado Futuro de Café: Um Estudo de Caso. Revista de Estudos Sociais. V.13. n. 26, 2011. Disponível em:<

http://periodicoscientificos.ufmt.br/ojs/index.php/res/article/view/278>. Acesso em 20 de fev. 2018.

FERREIRA, L. T; SANTOS, J. Safra Brasileira de café corresponderá a $\mathbf{3 1 , 3 \%}$ da produção global em 2017. <https://www.embrapa.br/busca-de-noticias//noticia/19687846/safra-brasileira-de-cafe-correspondera-a-313-da-producaoglobalem2017>. Acesso em 01 jan. 2019.

GILSON, R. J; KRAAKMAN, R. (2014), Market efficiency after the financial crisis: it's still a matter of information costs, Virginia Law Review 100(2), 313-375. Disponível em: < http://www.virginialawreview.org/volumes/content/market-efficiencyafter-financial-crisis-its-still-matter-information-costs >. Acesso em 28 de fev. 2019.

GOMES, F. C. Determinação da razão de hedge: um estudo sobre as teorias de hedging Rev. Adm. Empr. Rio de Janeiro, 27(4)38-44 out./dez. 1987. Disponível em:< http://www.scielo.br/pdf/rae/v27n4/v27n4a05.pdf >. Acesso em $15 \mathrm{de} \mathrm{fev.} \mathrm{de}$ 2018.

F.C. O modelo de avaliação de ativos - The Capital Asset Pricing Model. Dissertação de mestrado, 1982.

GONÇALVES, E. P. S. Eficiência de hedging e taxa ótima de hedge: contratos futuros de depósitos interfinanceiros de um dia. Revista Brasileira de Economia. Rio de Janeiro - out/dez, 1993. Disponível em: < http://bibliotecadigital.fgv.br/ojs/index.php/rbe/article/viewFile/588/7941>. Acesso em 15 de jan. 2019.

GREENE, W.H. Econometric Analysis. Prentice Hall, Nova Jersey, 2012.

HARZER, J. H; COSTA, T. C; SILVA, W. V; SOUZA, A. Eficiência dos mercados futuros de commodities agrícolas aplicando-se o teste de cointegração. Rev. 
Adm. UFSM, Santa Maria, v. 5, n. 2, p. 336-353, Maio/Agosto. 2012. Disponível em:< file:///C:/Users/Windows\%207\%20x64/Downloads/5432-30923-2-

PB\%20(1).pdf>. Acesso em 28 fev. de 2019.

HULL, John. Fundamentos dos Mercados Futuros e de Opções. 4. ed. São Paulo: BM\&F, 2005.

HULL, J. Introdução aos Mercados Futuros e de Opções. São Paulo: Cultura Editores Associados e Bolsa de Mercadorias \& Futuros, 1994.

KOENKER, R; BASSETT Jr, G. Regression Quantiles. Econométrica 46(1) 33-50 Disponível em

$<$ https://www.jstor.org/stable/1913643?origin=crossref\&seq=1\#page scan tab conte nts>, 1978. Acesso em 01 fev. 2019

LIM, K; BROOKS, R. (2011), The evolution of stock market efficiency over time: a survey of the empirical literature, Journal of Economic Surveys 25(1), 69-10. Disponível em:< https://papers.ssrn.com/sol3/papers.cfm?abstract id=1745754>. Acesso em 20 de fev. de 2019.

MARQUES, P. V; MELLO, P. C. Mercados futuros de commodities agropecuárias: exemplos e aplicações aos mercados brasileiros. São Paulo: BM\&F, 1999.

MENEGÁRIO, A. H; PAIVA, A. R. N; SOUZA, W. A. R; LIMA, M. S; FILHO, J. G. M. Eficiência Comparativa dos Mercados Futuros no Brasil e Exterior para a Comercialização da Safra e Café Brasileira. Pesquisa e Debate, Vol. 25, n. 1 (45) p. 25-51, São Paulo, jan. jun. 2014

OBSERVATORIO DO CAFÉ. Disponível em:

<http://www.consorciopesquisacafe.com.br/index.php/2016-05-27-17-07-18>

Acesso em 01 de jan. 2018.

OIC. Disponível em:<

http://www.ico.org/pt/about statistics p.asp?section=Estat\%EDstica> Acesso em 01 jan. 2018.

RIBEIRO, K.C. S; SOUSA, A.F; ROGERS, P. Preços do Café no Brasil: Variáveis Preditivas no Mercado à Vista e Futuro. Revista de Gestão USP, São Paulo v. 13n., janeiro/março 2006.

RIGHI, M. B; CERETTA, P. S. (2011), Previsibilidade e eficiência no mercado Agrícola, Ciência Rural 41(10), 1844-1850.

RODRIGUES, M. A.; MARTINES-FILHO, J. G. Eficiência nos mercados futuros agropecuários brasileiros. Economia Aplicada, v. 19, n. 2, April /June, 2015.

ROUTLEDGE, B. R.; SEPPI, D. J.; SPATT, C. S. Equilibrium Forward Curvas for Commodities, The Journal of Finance, v. LV, n. 3, p. 1297-1338, June 2000.

RUFINO, J. L. S; SOUSA, L. O; FERREIRA, M. D. Evolução e perspectivas para preço do 
café<https://www2.cead.ufv.br/espacoProdutor/scripts/verArtigo.php?codigo=26\&aca o=exibir >, 2011 Acesso: 01, fev. 2018

SABUHORO, J. B.; LARUE, B. The market efficiency hypothesis: The case of coffee and cocoa futures. Agricultural Economics, v. 16, Issue 3, August 1997, p. 171- 184.

SAMUELSON, P. A. Proof that properly anticipated prices fluctuate randomly. Industrial Management Review, Cambridge, v. 6, p. 41-49, 1965.

SILVA NETO, L. A. Derivativos: Definição, Emprego e Risco. São Paulo: Atlas, 1998.

WESTON, J. F; BRIGHAM, Eugene. Fundamentos da Administração Financeira. 10. ed. Tradução Sidney Stancatti. São Paulo: Makron Books, 2000.

\section{NOTAS DE AUTOR}

\section{CONTRIBUIÇÃO DE AUTORIA}

Brena do Nascimento Carvalho - Revisão, discussão conceitual e metodológica.

Ingrid Lorrane de Sousa Miranda - Revisão, discussão conceitual e metodológica.

Tarcísio da Costa Lobato- Orientação, Revisão e Aprovação final do Trabalho.

\section{FINANCIAMENTO}

Não se aplica.

\section{CONSENTIMENTO DE USO DE IMAGEM}

Não se aplica

APROVAÇÃO DE COMITÊ DE ÉTICA EM PESQUISA

Não se aplica

\section{CONFLITO DE INTERESSES}

Informar conflitos de interesse: financeiros, pessoais, entre possíveis revisores e editores, possíveis vieses temáticos. Para mais informações: https://www.abecbrasil.org.br/arquivos/whitepaper_CSE.pdf

\section{LICENÇA DE USO}

Este artigo está licenciado sob a Licença Creative Commons CC-BY. Com essa licença você pode compartilhar, adaptar, criar para qualquer fim, desde que atribua a autoria da obra.

\section{HISTÓRICO}

Recebido em: 03-07-2019

Aprovado em: 16-01-2020 